\title{
Lymphoma in the brain of a dog
}

Melissa N Andruzzi ${ }^{1}$, J oe M Mankin ${ }^{1}$, Carmen H Lau ${ }^{2}$, Richard J Ploeg ${ }^{2}$, Zacharia A Grami ${ }^{3}$,
Nick D Jeffery ${ }^{1 *}$

${ }^{1}$ Department of Small Animal Clinical Sciences and ${ }^{2}$ Department of Veterinary Pathology, College of Veterinary Medicine, Texas A\&M University, College Station, TX 77843, USA

${ }^{3}$ MSIV McGovern Medical School, Houston, TX 77030, USA

* Corresponding author

Address: as above

Email: njeffery@cvm.tamu.edu

Phone: (+1) 9792133366

This is the author manuscript accepted for publication and has undergone full peer review but has not been through the copyediting, typesetting, pagination and proofreading process, which may lead to differences between this version and the Version of Record. Please cite this article as doi: 10.1111/jsap.13095

This article is protected by copyright. All rights reserved. 


\title{
Lymphoma in the brain of a dog
}

\author{
Melissa N Andruzzi ${ }^{1}$, J oe M Mankin ${ }^{1}$, Carmen H Lau², Richard J Ploeg², Zacharia A Grami ${ }^{3}$, \\ Nick D Jeffery ${ }^{1 *}$
}

\begin{abstract}
${ }^{1}$ Department of Small Animal Clinical Sciences and ${ }^{2}$ Department of Veterinary Pathology, College of Veterinary Medicine, Texas A\&M University, College Station, TX 77843, USA

${ }^{3}$ MSIV McGovern Medical School, Houston, TX 77030, USA
\end{abstract}

* Corresponding author

Address: as above

Email: njeffery@cvm.tamu.edu

Phone: (+1) 9792133366

The images are of an 8-year-old female spayed Staffordshire bull terrier that presented with a 3-day history of acute rapidly progressive central vestibular signs. There was also a $3 \mathrm{~cm} x$ $3 \mathrm{~cm}$ region of reddened skin with macules on the ventrum; previous fine needle aspirates had suggested histiocytoma. MRI revealed abnormalities consistent with permeability of the blood-brain barrier and oedema of sufficient severity to consider CSF sampling hazardous (Fig.1). A prominent differential diagnosis was meningoencephalomyelitis of unknown origin (MUO), although tests for infectious diseases were also submitted. Because of the deteriorating neurologic status, immunosuppressive treatment (cytarabine IV infusion and dexamethasone IV) was commenced, along with oral clindamycin and doxycycline. Skin biopsy was delayed because of recent glucocorticoid administration and the dog's incontinence. Neurologic status improved considerably during 7 days' hospitalization, but then rapidly deteriorated through profound ataxia, opthalmoplegia and fatal cardiac

This article is protected by copyright. All rights reserved. 
arrhythmia within 16 days of initial presentation. Post mortem histopathology supported a diagnosis of T-cell lymphoma in both the brain and skin (Supplementary Fig. 1). PARR confirmed that both tissues were infiltrated by similar monoclonal neoplastic cell populations.

The therapeutic dilemma presented by this case is well-known and definitive diagnosis can only be made through histopathology. However, it highlights the need to consider the potential to obtain diagnostic information from organs outside the nervous system in some animals tentatively diagnosed with MUO. Our experience with this case might also suggest that immunosuppressive therapies which also target CNS lymphoma (for example corticosteroids plus lomustine) may be better treatment options for suspected MUO when lymphoma cannot be excluded. On the other hand, such therapy would increase risk of exacerbating infectious disease (if present) and, furthermore, even with appropriate treatment, the prognosis for CNS lymphoma in dogs is poor.

This article is protected by copyright. All rights reserved. 
Figure 1: A: mid-sagittal T2W MR image showing regions of hyperintensity in the cerebellum and apparent dilatation of the cerebral aqueduct, plus evidence of early cerebellar herniation (arrow); B: transverse T2W MR image at the level of the tentorium showing widespread hyperintensity in the cerebellum, brainstem and cerebral hemispheres; C: T1W MR post-contrast image at same level as B, illustrating enhancement of the meninges adjacent to the tentorium and patchy enhancement within the brainstem, especially on the right side; D: photograph of ventral skin showing hairless raised reddened region adjacent to midline.

This article is protected by copyright. All rights reserved. 

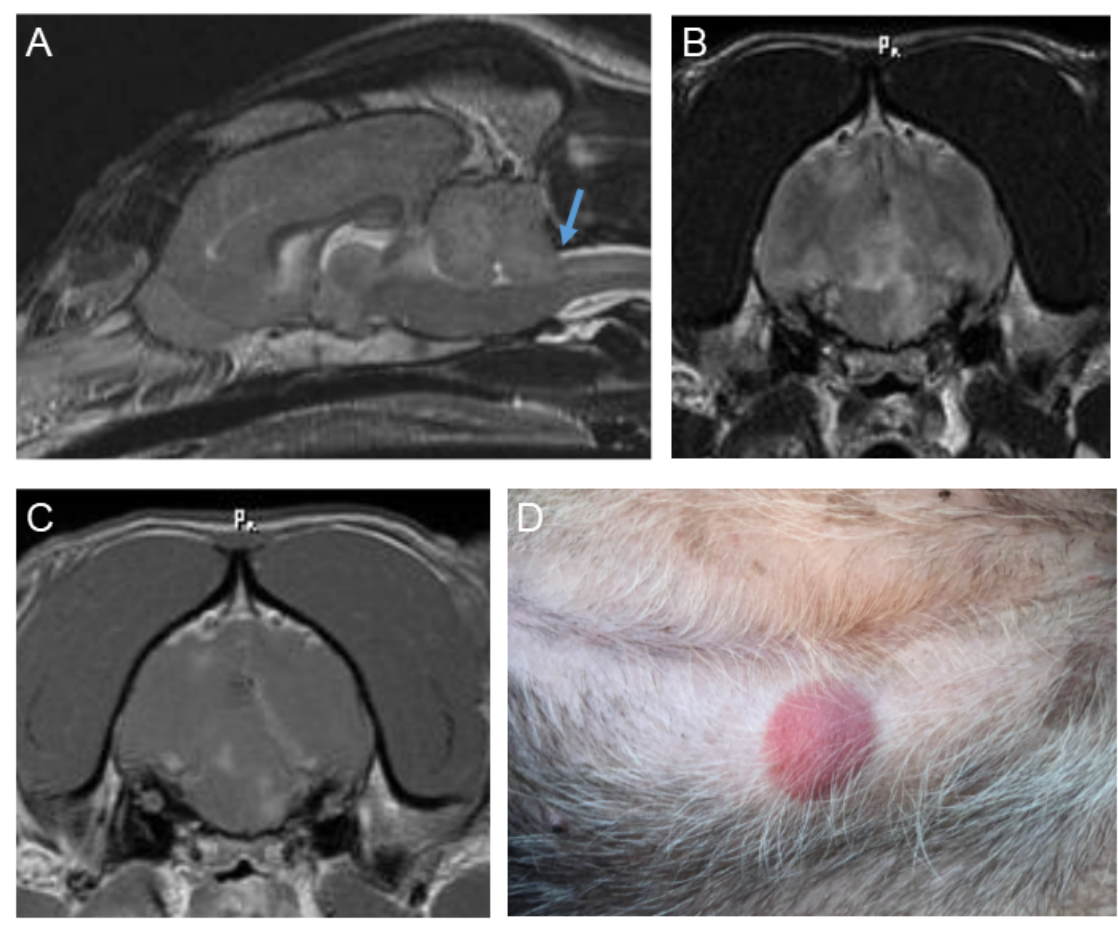

Figure 1

This article is protected bAP copyright. 13094 Fire 1 tifif 


\section{University Library}

\section{- M M I N E R VA A gateway to Melbourne's research publications}

Minerva Access is the Institutional Repository of The University of Melbourne

Author/s:

Andruzzi, MN;Mankin, JM;Lau, CH;Ploeg, RJ;Grami, ZA;Jeffery, ND

Title:

Lymphoma in the brain of a dog.

Date:

2020-04

Citation:

Andruzzi, M. N., Mankin, J. M., Lau, C. H., Ploeg, R. J., Grami, Z. A. \& Jeffery, N. D.

(2020). Lymphoma in the brain of a dog.. J Small Anim Pract, 61 (4), pp.263-264. https:// doi.org/10.1111/jsap.13095.

Persistent Link:

http://hdl.handle.net/11343/286772 